\title{
Grants awarded to research libraries to provide national access to resources
}

$\boldsymbol{0}$ n August 21, 1991, the U.S. Department of Education awarded $\$ 5,854,924$ in grants to 33 major research libraries in 19 states under the Strengthening Research Library Resources Program, Higher Education Act Title II-C.

Administered by the Department's Office of Library Programs within the Office of Educational Research and Improvement, the II-C program awards funds to research libraries to make accessible collections that are rare, exclusively held, and of interest to a national research audience. Program purposes are achieved by funding the production of machine-readable catalog records for contribution to national databases; by funding conservation and preservation of the research resources; and by funding the acquisition of rare and unique research materials to fill in gaps and strengthen existing collections.

Taking into account joint projects, the program awarded funds to 33 different research libraries. These projects will benefit the more than 12,000 member libraries

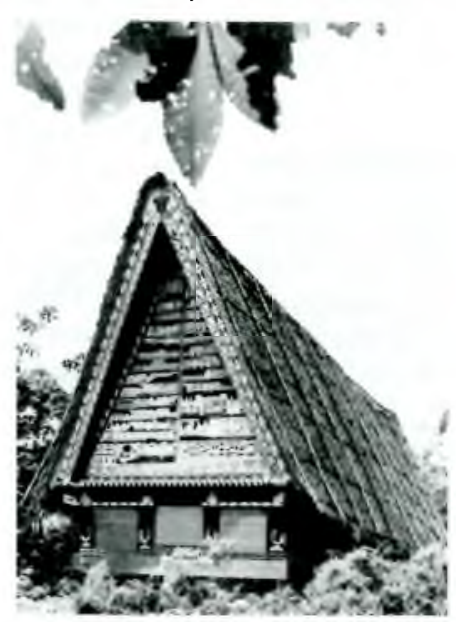

A Palauan bai built by the Melekeok community, Palau Islands. scanning 12,000 photographs and linking these images to the existing MARC (machine readable catalog) records. The MARC records will be enhanced and edited to provide detailed information regarding the content of the photographs including names of individuals, locations, and historical events. This database will be available to researchers via UMH's local online catalog and to any library or individual via CARL (Colorado Alliance of Research Li-
braries), an independent, regional, automated library network available to over 80 libraries nationally. CARL is also available via the Internet, opening access to the system to anyone with a modem. In addition, a published guide will be distributed to interested research institutions and organizations worldwide.

The Trust Territory Photo Collection is a unique resource that documents the history of the American period in Micronesia (19471988), and includes invaluable representations of island cultures. It contains of the two national bibliographic utilities, OCLC (Online Library Computer Center) and RLIN (Research Libraries Information Network), and the thousands of members of the local and regional networks in which the grantees participate.

An example of an HEA II-C project containing both preservation and bibliographic control activities is underway at the University of Hawaii, Manoa (UHM). The UHM library was awarded $\$ 148,779$ to create a digitized database of photographs from the Trust Territory Archives. This project will give scholars access to visual images linked to catalog records, allowing comprehensive use of this unique research material for the first time.

Utilizing newly available technology, UHM will create a digitized photograph database by photographs created for the Public Affairs Department, for Trust Territory publications such as Highlights and the Micronesian Reporter, and for the Trust Territory Department of Education.

Applications for these awards are encouraged. Watch the June Federal Register for the announcement of deadlines for the fiscal year 1993 awards. Tentative deadlines are October 1992 for eligibility and November 1992 for project applications.

For further information about funded projects or to obtain application materials, contact Linda Loeb or Louise Sutherland at the U.S. Department of Education, Library Programs, (202) 2191315-Linda Loeb, program officer, library programs, U.S. Department of Education; bitnet: l3o@NIHCU. 